DOI: 10.12731/2658-6649-2020-12-1-34-47

UDC 637.1

\title{
TYPOLOGY OF BUILDINGS FOR DAIRY COWS IN BOSNIA AND HERZEGOVINA
}

\section{Tanja Trkulja, Miljan Erbez}

In this paper, emphasis is on the clarification of existing models of dairy cows building $(D B S)$ designs in Bosnia and Herzegovina (BA) in order to define their typology. The aim is to define the typologies of DBs with regard to existing design patterns and the analysis of the built objects. Several methodological procedures were applied in the collected data analysis. It is necessary to define the criteria for the classification of the DBs types and present a part of the results obtained during the conducted research. The criteria for this classification are: the productive herd size in DBs, base useful surface area of DBs; the form of the DBs base; the height of the DBs facade walls and the existence of roof openings on the DBs. Five main types and thirteen subtypes were marked. Their construction is complex and some design solutions (doors, loft area, height of the walls etc.) significantly determine the possibilities for further development of the farms.

Keywords: Architecture; Buildings for dairy cows; Construction; Typology; Bosnia and Herzegovina.

\section{INTRODUCTION}

Within the architectural design methodology, the research process can be described as a search for an appropriate conceptual concept and an architectural solution for buildings of a particular typology. It starts by exploring the contextual conditions and potentials of the subject location on one side and the design parameters on the other side. All typologies of architectural buildings have their own specificities. Some of them are dominant, widespread and common in project practice (for example housing), while some are specific, unattainable and rarely projected. One of these specific typologies is buildings for dairy cows as crucial part of agricultural facilities.

Animals living on farms must feel comfortable, show good reproductive and productive characteristics, and eventually achieve good production. When designing and constructing a barn, it is necessary to pay special attention to the 
use of modern technologies and equipment, because well-designed and wellequipped facilities enable high productivity and rationalization of individual work operations (feeding, milking, manure cleaning). Space where animals feel comfortable and where all the technological processes are conducted according to plan represent the starting point of economically justified livestock production (Trkulja, Erbez, 2018).

The level of sustainability of animal production depends on the use of modern housing systems. These systems ensure high productivity and quality of milk and meat and make the robotization of work possible. At the same time, they minimize the negative impact on the environment, including energy inputs by using renewable energy sources and ensuring livestock welfare (Borusiewicz, Mazur, 2017). However, it is necessary to take into account and understand the current practices in housing of domestic animals, as it is not economically justified and expected that each farmer makes a new barn in order to follow all the instructions.

Typologies offer a framework for analysing the technical issues in agricultural production, developing a range of relevant solutions adjusted to the needs and means of different types of farms and planning development operations (Landais, 1998). Typification of farming systems can also be an important tool as a component of an effective methodology for delimitation and categorisation of less-favoured areas (Bignal, McCracken, 1996; Zabbini et al., 2007; Mądry, 2016).

Landais (1998) also suggests that typologies contribute to improving the efficiency of the two basic remits of agricultural advisors. They help carrying out the diagnoses of farm functioning and advising farmers in terms of techno-economy. The comparison of the farm being analysed to other farms which are considered to be viable and of same type is what makes the basis of the advisors' work. Such comparisons involve bodies of techno-economic references indicating the values assumed by a set of variables which describe the structure and performances of a sample of farms in each type. Typologies serve as a frame for organising and structuring the references in the field.

In this paper, emphasis is on the clarification of existing models of DBs designs in BA in order to define their typology with regard to existing realized patterns (realized buildings). The aim of this paper is to define the typologies of DBs with regard to existing performed facilities and conducted analysis. The intention is to point out the possibility of defining the typology for this type of agricultural facilities and to clarify the existing architectural solutions for dairy cows housing in BA. 


\section{MATERIALS AND METHODS}

The research was conducted from December 5, 2013 to March 15, 2014. Totally 76 herds were visited once by a team of trained observers in eighteen municipalities in BA. On seventy farms, cows were tie-housed, and in just six farms in loose housing systems (cubicles or deep straws). Farms consisted of five to one hundred seven dairy cows per herd. Herds were visited between 7:30 a.m. and 3:00 p.m. Herds were located from 90 to 1, 200 meters above sea level, which reflects the actual dispersion of BA dairy sector. The measurement of height, width and length of the DBs was conducted by Laser distance meter PCE-LDM50 with measurement range of $0.05-50 \mathrm{~m}$ and accuracy of $\pm 1.5 \mathrm{~mm}$. A systematic protocol was used in order to record data on each farm. This protocol was an adapted version of the one used in the Norwegian KUBYGG-project (Simensen et al., 2010).

Several methodological procedures were applied in the analysis of the collected data, which were focused on specific phases. The first part of the research implies the definition and analysis of the criteria for classifying the types of DBs. Based on the collected data all this is explained in the first part of the survey. The processing of collected data is determined by the methods of structural, functional and causal analysis, but also by the application of the induction method, reasoning from particular to general. This is because the types are defined for each criterion, in which the similar DBs are classified. Critical analysis, systematization and evaluation of the collected results of the empirical research indicate the state of the existing DBs in BA. This part of the research is based on the logical argumentation method because the research is based on theoretical clarity and involves the establishment of precisely defined relationships between the criteria.

The second part of the study involves the design of a typology for DBs. First, all the obtained results in the analysis of the criteria by synthesis are related to the basic typology formed on the basis of the number of herds. Then subtypes were formed for each type of DBs using the deduction method, reasoning from general to particular. In order to present the synthesized tabular presentation of the DBs typology, all the DBs have been approached and described individually. The results and contribution of the work are logically presented and argued in the concluding chapter.

\section{RESULTS}

The research results were derived from the analysis of the existing design patterns and built DBs in BA. The criteria for classifying the types of DBs and their analysis were defined first, and then their typology was defined. 


\subsection{Analysis of criteria for classification of DBs' types in BA}

In this regard, the criteria for classifying DBs types are:

- productive herd size in the DBs;

- base useful surface area of the DBs (net surface);

- the form of the DBs base;

- the height of the DBs facade walls;

- the existence of roof openings on the DBs.

The basic typology based on the size of the productive herds is defined, while other criteria influence the classification of subtypes of the DBs.

\subsubsection{Productive herd size in the DBs}

In Table 1, there is a basic DBs typology, which is made according to productive herd size - i.e. number of dairy cows in the herd at the moment of visit.

Table 1 .

Basic typology of DBs according to productive herd size

\begin{tabular}{|c|c|c|}
\hline Type & Production herd size & Number of DBs \\
\hline T1 & 5-10 dairy cows & 36 \\
\hline T2 & $11-20$ dairy cows & 19 \\
\hline T3 & 21-30 dairy cows & 12 \\
\hline T4 & 31-50 dairy cows & 4 \\
\hline T5 & $>51$ dairy cow & 5 \\
\hline
\end{tabular}

This DBs analysis by number of herds primarily affects the conceptualization of the basic typology of the DBs, which defines the five basic types.

\subsubsection{Base useful surface area of the DBs}

In order to analyze the base useful surface area of DBs (Table 2), the ranges that depend on the number of animals (basic typology) were established.

Table 2.

Base useful surface area DB according to productive herd size

\begin{tabular}{|c|c|c|}
\hline Type & $\begin{array}{c}\text { Base useful surface } \\
\text { area of DBs }\end{array}$ & $\begin{array}{c}\text { The classification of types according to the base } \\
\text { useful surface area of DBs }=\text { number of DBs }\end{array}$ \\
\hline $\mathrm{T} 1$ & $40-254,2 \mathrm{~m}^{2}$ & $40-80 \mathrm{~m}^{2}=25 ; 80-200 \mathrm{~m}^{2}=10 ;=200 \mathrm{~m}^{2}=1$ \\
\hline $\mathrm{T} 2$ & $46,7-317,5 \mathrm{~m}^{2}$ & $40-120 \mathrm{~m}^{2}=12 ; 120-220 \mathrm{~m}^{2}=5 ;=220 \mathrm{~m}^{2}=2$ \\
\hline $\mathrm{T} 3$ & $58,1-548 \mathrm{~m}^{2}$ & $60-180 \mathrm{~m}^{2}=4 ; 180-300 \mathrm{~m}^{2}=6 ;=300 \mathrm{~m}^{2}=2$ \\
\hline $\mathrm{T} 4$ & $132,3-576 \mathrm{~m}^{2}$ & $100-300 \mathrm{~m}^{2}=2 ; 400-600 \mathrm{~m}^{2}=2$ \\
\hline $\mathrm{T} 5$ & $318,7-2511,3 \mathrm{~m}^{2}$ & $300-500 \mathrm{~m}^{2}=3 ; 1800-2500 \mathrm{~m}^{2}=2$ \\
\hline
\end{tabular}




\subsubsection{The form of the DBs base}

The form of the DBs base implies the relationship between the length and the width of the building and refers to three basic divisions: buildings with square base (ratio about 1:1), buildings with rectangular base (the ratio of $1: 1.5-1: 2.5$ ), and buildings with an elongated rectangular base (the ratio of $1: 3-1: 3.5)$.

The analysis showed that DBs of up to ten cows mostly have the rectangular base ( $94 \%$ or $34 \mathrm{DBs})$. Two DBs have the elongated rectangular base $(6 \%)$. DBs with eleven to twenty cows are also mainly of rectangular base (18 DBs or $95 \%$ ), while only one DB has an elongated rectangular base (5\%).

DBs with twenty-one to thirty cows are again mainly with rectangular base (9 DBs or $75 \%$ ), two DBs have a square base (17\%), while only one DB has an elongated rectangular base (8\%). DBs with a square base exist only within this type.

DBs with thirty-one to fifty cows are equally with rectangular (2 DBs or $50 \%$ ) and an elongated rectangular base (2 DBs or $50 \%$ ). DBs with more than fifty-one cows are mainly with rectangular base (4 DBs or $80 \%$ ), while only one DB has an elongated rectangular base $(20 \%)$.

With the analysis of all the seventy-six DBs, regardless of the number of dairy cows, it is concluded that the DBs with a rectangular base are dominant ( $88 \%$ or $67 \mathrm{DBs})$. Seven of DBs have elongated rectangular base $(9 \%)$ and only two DBs $(3 \%)$ have a square base.

\subsubsection{The height of the facade walls of the $D B s$}

The analysis of the DBs according to the height of the facade walls has also been done within the basic typology according to the number of animals. Three types were defined: low-rise buildings (height 1.8-2.5 m), medium-rise buildings (height 2.5-3.5 m) and high-rise buildings (height 3.5-4.5 m). The analysis shows that small DBs of up to ten cows are mostly low-rise buildings (26 DBs or $72 \%$ ) and medium-rise buildings (10 DBs or $28 \%$ ). Dairy buildings with eleven to twenty cows are also mostly low-rise buildings ( 9 DBs or $47 \%$ ), medium-rise buildings (7 DBs or 37\%) and high-rise buildings (3 DBs or $16 \%$ ).

Dairy buildings with twenty-one to thirty cows are mostly medium-rise buildings (9 DBs or $75 \%$ ). Two DBs are low-rise buildings are $(17 \%)$ and only one of them is a high-rise building (8\%). Dairy buildings of thirty-one to fifty cows are mostly high-rise buildings ( $3 \mathrm{DBs}$ or $75 \%$ ) and one is a medium-rise building (25\%). 
Dairy buildings with more than fifty-one cows are equally low-rise (2 DBs or $40 \%$ ) and medium-rise buildings (2 DBs or $40 \%$ ), while only one is highrise building $(20 \%)$. When looking at the analysis of all the seventy-six DBs, regardless of the number of cows, the low-rise buildings are dominant (39 DBs or $51 \%$ ). These are followed by the medium-rise buildings (29 DBs or $38 \%$ ) and high-rise buildings ( 8 DBs or $11 \%$ ).

\subsubsection{The existence of roof openings on the DBs}

Two types of DBs are defined in relation to the existence of roof openings: DBs with roof opening and DBs without a roof opening. The analysis shows that small DBs of up to ten cows are mostly without a roof opening (34 DBs or $94 \%$ ), while $6 \%$ of the DBs are with the roof opening (2 DBs). Dairy buildings with eleven to twenty cows are also mostly without a roof opening (16 DBs or $84 \%$ ), while $16 \%$ are with a roof opening (3 DBs). DBs with twenty-one to thirty cows are equally without a roof opening (6 DBs or $50 \%)$ and with a roof opening (6 DBs or 50\%). Dairy buildings of thirty-one to fifty cows are also equally without a roof opening $(50 \%$ or $2 \mathrm{DBs})$ and with a roof opening (2 DBs or $50 \%$ ).

Dairy buildings with more than fifty-one cows are mainly with a roof opening (4 DBs or $80 \%$ ), while only one DB $(20 \%)$ is without the roof opening. The analysis performed on seventy-six DBs shows that there are fifty-nine DBs $(78 \%)$ without the roof opening and seventeen DBs with the roof opening $(22 \%)$.

\subsection{Typology of DBs}

The DBs typology has been primarily based on the analysis according to the herd size (excluding calves). Five types have been identified and those were enriched with the characteristics defined by the analyzed criteria. Characteristics are assigned to types in relation to the dominant number of DBs appearing within certain criteria. The table shows the illustrations of types where the DBs are presented with minimal dimensions (for example: for T1a - surface area 40 $\mathrm{m}^{2}$, rectangular base $1: 1.5$, low DB height of facade walls $1.8 \mathrm{~m}$ and without roof opening).

The maximal dimensions of DBs are provided with a shaded base surface and a dotted line of the structure of the building (for example: for T1a $-80 \mathrm{~m}^{2}$ area, rectangular base ratio 1:2.5, low DBs height of facade walls $2.5 \mathrm{~m}$ and without roof opening). Synthesis of the DBs types and their basic characteristics are shown in detail in Fig. 1. 


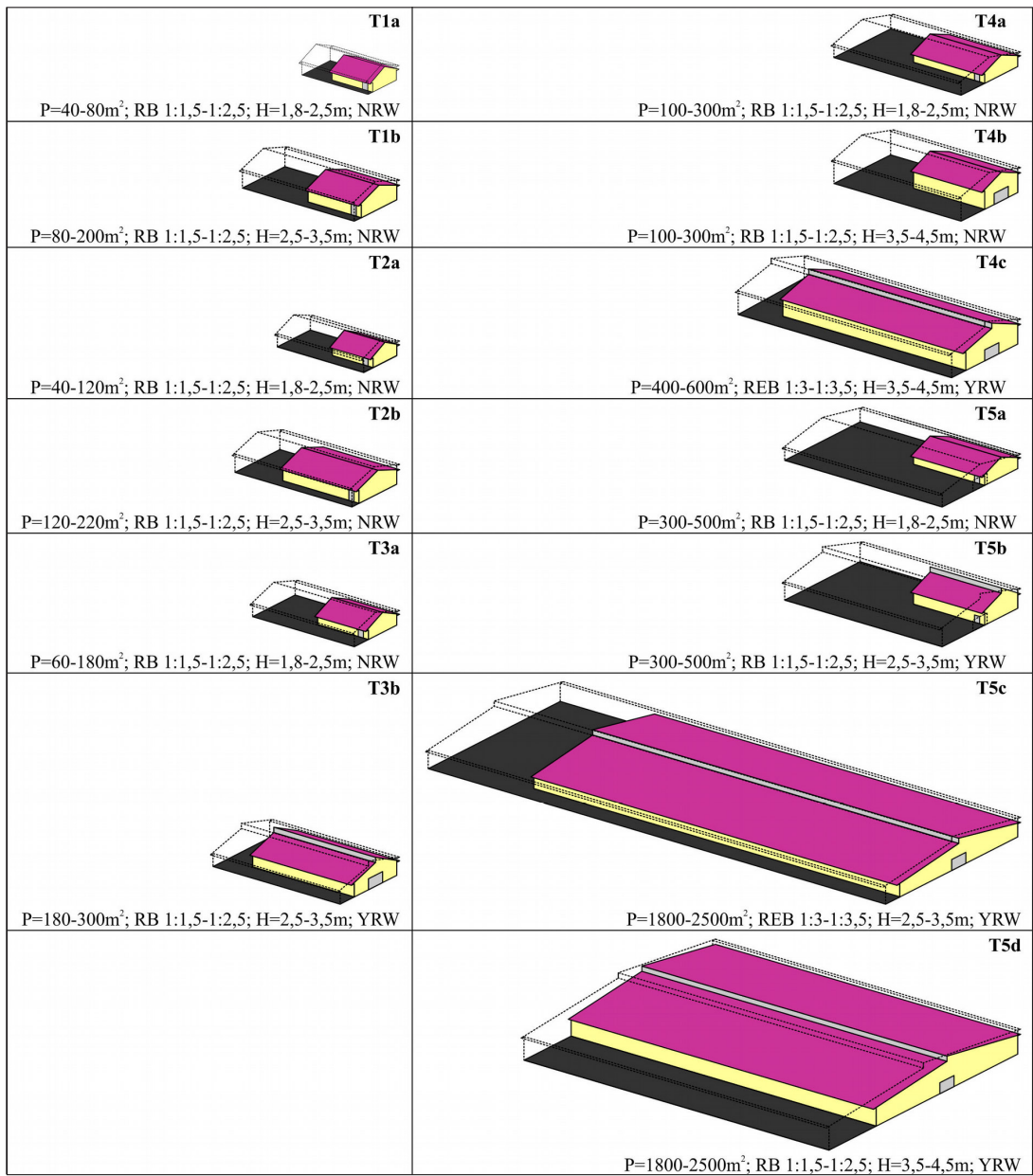

Fig. 1. Synthesis view and basic characteristics of DBs' types / subtypes $(\mathrm{P}=$ useful surface area of the $\mathrm{DBs} ; \mathrm{RB}=$ rectangular base form; $\mathrm{REB}=$ rectangular elongated base form; $\mathrm{H}=$ height of the facade walls of the DBs; YRW = with roof opening on the DBs; NRW = no roof opening on the DBs).

\subsubsection{Type 1 (Subtypes T1a and T1b)}

Type 1 represents the DBs with a productive herd of five to ten dairy cows. It occurs in two subtypes that differ in the surface of the building and the height of the facade walls. Subtype T1a represents the DBs surface area of 40 to 80 
$\mathrm{m}^{2}$ and low building height of facade walls from 1.8 to $2.5 \mathrm{~m}$. The second one, subtype T1b is buildings of the base area of 80 to $200 \mathrm{~m}^{2}$ and medium high DBs height of facade walls from 2.5 to $3.5 \mathrm{~m}$. In both subtypes, DBs are with rectangular base (ratio of width and length 1:1.5 - 1:2.5) and without roof opening.

\subsubsection{Type 2 (Subtypes T2a and T2b)}

Type 2 represents DBs with a productive herd of eleven to twenty dairy cows. It occurs in two subtypes that also differ in the surface of the building and the height of facade walls. Subtype T2a represents DBs surface area of 40 to $120 \mathrm{~m}^{2}$ and low height of facade walls from 1.8 to $2.5 \mathrm{~m}$. On the other hand, subtype T2b represents DBs surface area of 120 to $220 \mathrm{~m}^{2}$ and medium-rise building height of facade walls from 2.5 to $3.5 \mathrm{~m}$. In both subtypes, buildings are with rectangular base (ratio of width and length 1:1.5 - 1:2.5) and without a roof opening.

\subsubsection{Type 3 (Subtypes T3a and T3b)}

Type 3 represents DBs with a productive herd of twenty-one to thirty dairy cows. It occurs in two subtypes that differ in the surface of the building, the height of the facade walls and the existence of the roof opening. Subtype T3a represents the DBs surface of the base of 60 to $180 \mathrm{~m}^{2}$, which have a low height of facade walls from 1.8 to $2.5 \mathrm{~m}$ and without a roof opening. On the other hand, subtype T3b represents DBs surface area of 180 to $300 \mathrm{~m}^{2}$, which are medium-rise high facade walls of 2.5 to $3.5 \mathrm{~m}$ and with a roof opening. In both subtypes DBs are with rectangular base (ratio of width and length $1: 1.5-1: 2.5)$.

\subsubsection{Type 4 (Subtypes T4a, T4b and T4c)}

Type 4 represents DBs with a productive herd of thirty-one to fifty dairy cows. It occurs in three subtypes, out of which subtype T4a and subtype T4b differ only in height of facade walls, while their other characteristics are the same. Subtype T4a represents low-rise buildings, with the facade walls from 1.8 to $2.5 \mathrm{~m}$ high, while subtype T4b represents buildings of high facade walls of 3.5 to $4.5 \mathrm{~m}$. Both subtypes represent DBs surface area of 100 to $300 \mathrm{~m}^{2}$, with a rectangular base (ratio of width and length 1:1.5 - 1:2.5) and without a roof opening. The subtype T4c represents the DBs surface of the base of 400 to $600 \mathrm{~m}^{2}$, which are of elongated rectangular base (ratio of width and length 1:3 - 1:3.5) and with the roof opening. These are high buildings with the facade walls of 3.5 to $4.5 \mathrm{~m}$ high. 


\subsubsection{Type 5 (Subtypes T5a, T5b, T5c and T5d)}

Type 5 includes DBs with a productive herd with more than fifty-one dairy cows and those were dominantly loose housing barns. It appears in four subtypes, of which subtype T5a and subtype T5b have the same surface area of 300 to $500 \mathrm{~m}^{2}$, of rectangular base (ratio of width and length 1:1.5 - 1:2.5). Subtype T5a is a low-rise building with the facade walls of 1.8 to $2.5 \mathrm{~m}$ high and without a roof opening, while the subtype T5b is a medium-rise building with the facade walls from 2.5 to $3.5 \mathrm{~m}$ high and with a roof opening. Subtypes T5c and T5d also have the same surface area, much larger than the previous two subtypes - from 1800 to $2500 \mathrm{~m}^{2}$ and appear with the roof hole. Objects belonging to subtype T5c have elongated rectangular base (ratio of width and length 1:3 - 1:3.5) with medium height of facade walls - from 2.5 to $3.5 \mathrm{~m}$. The subtype T5d represents buildings of rectangular base (ratio of width and length 1:1.5 $1: 2.5$ ) with high facade walls - from 3.5 to $4.5 \mathrm{~m}$.

\section{DISCUSSION}

The majority of the farms visited in this research were small-scale farms, as it is typical for BA dairy sector (FAO, 2012; Glavić et al., 2017; Erbez et al., 2018). The analysis performed on seventy-six DBs shows that the surface of the DBs base does not depend on the productive herd size. For example, the surface of the base of $130 \mathrm{~m}^{2}$ has DBs with a herd size of five to thirty-one cows. This points to the fact that in individual stalls with less animals space for cows is also used for other functions (storage of machinery and feedstuffs for example), or to the fact that some DBs have been inadequately built. Similar findings were recorded in Norway, where there were large variations of the size of spaces allocated for lactating cows in free stall barns, with 5.9 to $12.9 \mathrm{~m}^{2}$ per a barn. Inadequate use of barn space could also be the reason of the inefficiency of small farms (Naess, Stokstad, 2011). Consequently, there is a lack of possibilities for investment (new animals, farm equipment, etc.) and according to Mazur et al. (2015) highest labour inputs.

When analyzing the form of DBs base, there were no special differences among the farms. Majority of the farms were of rectangular shape, which is almost regular approach in DBs construction regarding the farm management. However, this could also be due to better energy performance and heating in cold period of the year in comparison to the square shape (Tuhus-Dubrow, Krarti, 2010; Mokrzecka, 2018), as majority of the visited DBs had longer walls facing the south.

Majority of the DBs were with low or medium-rise buildings (89\%). There are several explanations of this. Firstly, the majority of farms were older (tie- 
stall housing system was in $92 \%$ of farms) and more demanding construction works on farm objects were not usual in private farms in the past. Secondly, the farmers probably thought that low-rise farms have lower energy consumption and thus were warmer in winter period. That is not always good for animals.

Roof openings are not quite common at visited barns in BA, especially the smaller ones. Therefore, this issue deserves better attention, primarily because of the importance of light in the barns since it affects the health of dairy cows. As it is known, the adequate amount of light could increase milk yield (Espinoza, Oba, 2017), but also health of animals (Dahl, Petitclerc, 2003).

In this research, five main types and thirteen subtypes were marked. The construction of the defined types/subtypes is complex and some design solutions (doors, loft area, height of the walls etc.) significantly determine the possibilities for further development of the farms. It is noticed that the number of dairy farms throughout the world has been decreasing while at the same time the number of the cows per herd has been increasing (Marco et al., 2008; Barkema et al., 2015). The authors didn't meet any similar findings in the available researches that deal with the DBs typology. Scientific papers are mainly related to the examination of the environmental impact on dairy farms (Bakken et al., 2017; Galloway et al., 2018), low-input dairy farming (Bijttebier et al., 2017), estimated release of nutrients into the environment on dairy farms (Schiavon et al., 2019), implementation of herd health plans (Blanco-Penedo et al., 2019), smart farming systems (Wolfert et al., 2017), designing agro-ecological farming systems with farmers (Lacombe, Couix, Hazard, 2018), etc. In BA, scientific papers are mainly engaged in the research: improving design of dairy cows housing (Trkulja, Erbez, 2018), indoor climatic status and welfare of dairy cows (Erbez et al., 2016; Važić et al., 2015; Jovović et al., 2014), etc.

\section{CONCLUSION}

It has been confirmed that there are many different approaches in the housing of dairy cows in BA. It can be noted that most farms are built according to the availability of sources, personal perception of constructors and their actual knowledge in the time when DBs were built. There is only a small number of DBs really intended for the purpose of housing of dairy cows and which fulfill the current understanding of dairy cows' welfare.

In this paper, concrete measures of DBs are given, i.e. the proportions of the DBs (base useful surface area, form of the base, height of the facade walls).

The paper also provides an overview of the individual functions that these buildings fulfill in terms of the welfare of animals, such as the existence of roof 
openings and access to daylight for animals. Taking into account all the above mentioned, the results of this research offer the starting point and information relevant for the acquisition of the adequate politics, strategies or planned solutions for the reconstruction of facilities, all in order to improve the dairy sector in BA or other countries with the similar situation in the housing of dairy cows. In addition, the typology of DBs can also help define environmentally friendly actions. Further research in this field should be directed to the analysis of the efficiency of milk production, working processes on farms and health and welfare of dairy cows within the defined types and subtypes of DBs. In this way, in the process of architectural design, it is possible to improve the existing patterns and approaches.

\section{ACKNOWLEDGEMENTS}

The authors wish to thank all the participating farmers for their help during the study. The study was financially supported by the Norwegian HERD programme [grant no. $332160 \mathrm{UU}$ ].

\section{References}

1. Bakken A.K., Daugstad K., Johansen A., Hjelkrem A.G. R., Fystro G., Strømman A.H., Korsaeth A., 2017. „Environmental impacts along intensity gradients in Norwegian dairy production as evaluated by life cycle assessments, “ Agricultural Systems 158(C), 50-60. DOI: 10.1016/j.agsy.2017.09.001

2. Barkema H.W., Von Keyserlingk M.A.G., Kastelic J.P., Lam T.J.G.M., Luby C., Roy J.P., Kastelic \& Kelton D.F., 2015. Invited review: Changes in the dairy industry affecting dairy cattle health and welfare. Journal of Dairy Science 98(11), 7426-7445. https://doi.org/10.3168/jds.2015-9377

3. Bignal E.M., McCracken D.I., 1996. Low-intensity farming systems in the conservation of the countryside. Journal of Applied Ecology 33(3), 413-424. DOI: $10.2307 / 2404973$

4. Bijttebier J., Hamerlinck J., Moakes S., Scollan N., Van Meensel J., Lauwers L., 2017. Low-input dairy farming in Europe: exploring a context-specific notion. Agricultural Systems 156, 43-51. http://dx.doi.org/10.1016/j.agsy.2017.05.016

5. Blanco-Penedo I., Sjöström K., Jones P., Krieger M., Duval J., Soest F., Sundrum A., Emanuelson U., 2019. Structural characteristics of organic dairy farms in four European countries and their association with the implementation of animal health plans. Agricultural Systems, 173, 244-253. https://doi.org/10.1016/j.agsy.2019.03.008

6. Borusiewicz A., Mazur K., 2017. Environmental and economic conditioning of the breeding of dairy cattle. Fresenius Environmental Bulletin 26(10), 5824-5832. 
7. Dahl G.E., Petitclerc D., 2003. Management of photoperiod in the dairy herd for improved production and health. Journal of Animal Science 81(3), 11-17. DOI: 10.2527/2003.81suppl_311x

8. Erbez M., Važić B., Rogić B., Bøe K.E., Ruud L.E., 2018. Cow cleanliness in dairy herds with tie stall systems in Bosnia and Herzegovina. Acta agriculturae Slovenica 112(1), 11-17. DOI: 10.14720/aas.2018.112.1.2

9. Erbez M., Važić B., Boe K.E., Ruud L.E., 2016. Indoor climatic status during winter conditions in dairy herds in Bosnia and Herzegovina. Acta argiculturae Slovenica, 108/2, 121-125. doi:10.14720/aas.2016.108.2.6

10. Espinoza O.S., Oba M., 2017. Interaction effect of photoperiod management and dietary grain allocation on productivity of lactating dairy cows. Canadian journal of animal science $97(3), 517-525$. https://doi.org/10.1139/cjas-2016-0234

11. FAO, Regional office for Europe and Central Asia. 2012. The meat and dairy sector in Bosnia and Herzegovina. Preparation of IPARD sector analyses in Bosnia and Herzegovina (Contract number 2010/256-560). Rome, Italy: FAO.

12. Galloway, C., Conradie, B., Prozesky, H., Esler, K., 2018. Opportunities to improve sustainability on commercial pasture-based dairy farms by assessing environmental impact. Agricultural Systems, 166, 1-9. https://doi.org/10.1016/j. agsy.2018.07.008

13. Glavić M., Zenunović A., Budiša A., 2017. The Production, Purchase and Processing of Milk in Bosnia and Herzegovina. Agro-knowledge Journal 18(3), 187-198. DOI: 10.7251/AGREN1703187G

14. Jovović V., Rogić B., Važić B., Bøe K.E., Ruud L.E., Erbez M., 2014. Examination of certain parameters affecting dairy cows' welfare in Bosnia and Herzegovina. In D. Kovačević (Ed.) Book of proceedings: Fifth International Scientific Agricultural Symposium „Agrosym 2014“ (pp. 854-858). Available Online: http://www.agrosym.rs.ba/agrosym/agrosym_2014/documents/PROCEEDINGS_2014.pdf

15. Lacombe C., Couix N., Hazard L., 2018. Designing agroecological farming systems with farmers: A review. Agricultural Systems, 165, 208-220. https:// doi.org/10.1016/j.agsy.2018.06.014

16. Landais E., 1998. Modelling farm diversity: new approaches to typology building in France. Agricultural systems, 58(4), 505-527. https://doi.org/10.1016/ S0308-521X(98)00065-1

17. Mądry W., Roszkowska-Mądra B., Gozdowski D., \& Hryniewski, R. (2016). Some aspects of the concept, methodology and application of farming system typology. Electronic Journal of Polish Agricultural Universities, 19(1). Available Online: http://www.ejpau.media.pl/volume19/issue1/art-12.html 
18. Marco J.L., Cuesta T.S., Resch C.J., Álvarez C.J., 2008. Analysis of layout design models using a multi-criteria function: dairy housing in Galicia (NW Spain). Transactions of the ASABE 51(6), 2105-2111. American Society of Agricultural and Biological Engineers. ISSN 0001-2351.

19. Mazur K., Barwicki J., Majchrzak M., Borek K.,Wardal W.J., 2015. Economic analysis of non-litter cattle barns. Agricultural Engineering 19(1(153)), 95-106. DOI: http://dx.medra.org/10.14654/ir.2015.153.110

20. Mokrzecka M., 2018. Influence of building shape and orientation on heating demand: simulations for student dormitories in temperate climate conditions. E3S Web of Conferences 44, 00117, EKO-DOK 2018. https://doi.org/10.1051/ e3sconf $/ 20184400117$

21. Næss G., Stokstad G., 2011. Dairy barn layout and construction: Effects on initial building costs. Biosystems engineering 109(3), 196-202. DOI: 10.1016/j. biosystemseng.2011.03.005

22. Schiavon S., Sturaro E., Tagliapietra F., Ramanzin M., Bittante G., 2019. Nitrogen and phosphorus excretion on mountain farms of different dairy systems. Agricultural Systems, 168(C), 36-47. https://doi.org/10.1016/j. agsy.2018.10.006

23. Simensen E., Østerås O., Bøe K.E., Kielland C., Ruud L.E., Næss, G., 2010. Housing system and herd size interactions in Norwegian dairy herds; associations with performance and disease incidence. Acta Vetarinaria Scandinavica 52, 14. doi:10.1186/1751-0147-52-14

24. Trkulja T., Erbez M., 2018. Improving design of dairy cows housing in Bosnia and Herzegovina". In: Proceedings of scientific conference with international participation Contemporary theory and practice in construction XIII, 510-524. DOI: 10.7251/STP1813510T; ISSN 2566-4484

25. Tuhus-Dubrow D., Krarti M., 2010. Genetic-algorithm based approach to optimize building envelope design for residential buildings. Building and environment, 45(7), 1574-1581. https://doi.org/10.1016/j.buildenv.2010.01.005

26. Važić B., Batinić V., Savić N., Erbez M., 2015. Characteristics of indoor microclimate status in goat barns in Bosnia and Herzegovina. Special Issue - Livestock Housing Conference, Journal of Animal Science of Bosnia and Herzegovina, 43-49. DOI: 10.7251/JAS1502043V

27. Zabbini E., Grandi S., Dallari F., 2007. Relative Remote Rural Areas (RRRA) in developed regions: An analysis of the Emilia-Romagna Region to support policy decision making. 1 - 29. MPRA Paper No. 4661, University Library of Munich, Germany. Available Online: http://mpra.ub.uni-muenchen. de/4661/ 
28. Wolfert S., Ge L., Verdouw C., Bogaardt M.J., 2017. Big Data in Smart Farming - A review. Agricultural Systems 153, 69-80. https://doi.org/10.1016/j. agsy.2017.01.023

\section{DATA ABOUT THE AUTHORS}

\section{Tanja Trkulja, Ph.D.}

University of Banja Luka, Faculty of Architecture, Civil Engineering and Geodesy

1A, Bulevar vojvode Petra, Bojovica 78000, Banja Luka, Republic of Srpska, Bosnia and Herzegovina tanja.trkulja@aggf.unibl.org

\section{Miljan Erbez, Ph.D.}

Ministry of Agriculture, Forestry and Water Management of Republic of Srpska, Livestock Production Department

1, Trg Republike Srpske, 78000, Banja Luka, Republic of Srpska, Bosnia and Herzegovina miljanerbez@gmail.com 